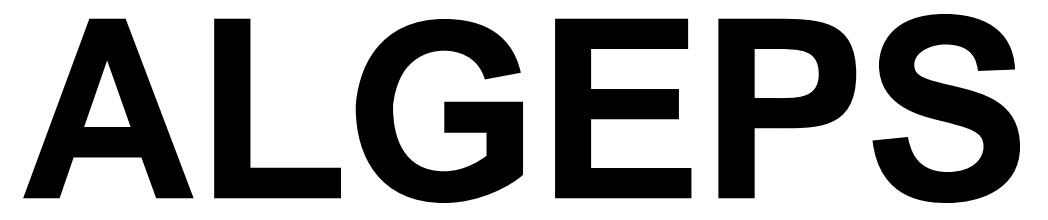

REVISTA DE GEOLOGIA, SÈRIE B $n^{\circ} 606$ - Octubre del 2012

ISSN 1132 - 7014

D.L.B. 28.178 - 92

10 pàgines

\begin{abstract}
RECORREGUT DE RECERCA GEOLÒGICA I MINERALÒGICA PER LES COMARQUES DE L'ALT CAMP I DE LA CONCA DE BARBERÀ: DES DEL PLA DE SANTA MARIA A FIGUEROLA DEL CAMP, CABRA DEL CAMP, SARRAL I A SANT MIQUEL DE MONTCLAR
\end{abstract}

Josep M. Mata-Perelló i Joaquim Sanz Balagué 


\section{RECORREGUT DE RECERCA GEOLÒGICA I MINERALÒGICA PER LES COMARQUES DE L'ALT CAMP I DE LA CONCA DE BARBERÀ: DES DEL PLA DE SANTA MARIA A FIGUEROLA DEL CAMP, CABRA DEL CAMP, SARRAL I A SANT MIQUEL DE MONTCLAR / 26b DE FEBRER DEL 2011}

Per Josep M. MATA-PERELLÓ i Joaquim SANZ i BALAGUÉ

\section{ADVERTIMENTS PREVIS}

Com en altres recorreguts de RECERCA GEOLÒGICA I MINERALÒGICA ..., si es disposa del temps suficient, poden efectuar-se passant per totes les parades i filloles. En cas contrari, recomanem prescindir de les anomenades PARADES - CONDICIONALS.

També recomanem de cercar la informació més adient, sobre els trams a recórrer mitjançant camins de terra, o de pista. Precisament, en aquest itinerari, hi ha alguns trajectes d'aproximació cap a les mines, que haurem de fer per camins de terra en irregular estat de conservació.

Per d'altra banda, recomanem tenir una cura extrema de la NATURA, evitant qualsevol forma d'agressió sobre ella, o de fer-n’hi un mal ús del que en ofereix la nostra mare Terra.

\section{BREU INTRODUCCIÓ}

En aquesta ocasió, el recorregut del present l'itinerari discorrerà exclusivament per dues de les tres unitats geològiques que constitueixen el nostre país, concretament pel Sistema Mediterrani per la Depressió Geològica de l'Ebre. Així, el recorregut śiniciarà a la primera de les dues unitats; concretament a la seva Depressió Prelitoral Catalana (Depressió del Camp), passant després cap a la Serralada Prelitoral Catalana, la seva unitat més externa. Tot seguit, la resta del recorregut es farà ja per la Depressió Geològica de l'Ebre. Tot i així, dintre d'aquesta, el recorregut discorrerà per dos dels seus sectors (MATA-PERELLÓ, 1995), concretament per la seva Depressió Central i també per un sector dels denominats Altiplans Meridionals.

Dintre del Sistema Mediterrani, el recorregut transitarà entre el Pla de Santa Maria i poc més enllà de Cabra del Camp. La resta del recorregut, entre aquesta darrera població, Sarral i Sant Miquel de Montclar, es farà sempre per la Depressió Geològica de l’Ebre.

Cal dir que la totalitat del recorregut discorrerà per dues comarques. S'iniciarà a la de l'Alt Camp, per on discorrerà entre el Pla de Santa Maria i Cabra del Camp. I finalitzarà a la 
comarca de la Conca de Barberà, per on discorrerà entre Cabra del Camp i Sant Miquel de Montclar.

\section{OBJECTIUS FONAMENTALS}

Els objectius que es pretenen aconseguir en aquest itinerari, es concretaran en els següents aspectes:

1.- Estudi i reconeixement de la Depressió Prelitoral Catalana (Depressió del Camp), per on es discorrerà al principi del recorregut, entre el Pla de Santa Maria i les immediacions de Figuerola del Camp. I alhora, reconeixement dels materials cenozoics que la rebles: del Miocè i del Quaternari.

2.- Estudi i reconeixement de la Serralada Prelitoral Catalana , per on es discorrerà el recorregut de l'itinerari, entre Figuerola del Camp i les immediacions de Cabra del Camp. I alhora, reconeixement dels materials que la constitueixen: del Mesozoic (del Triàsic, exclusivament) i del Paleozoic (del Carbonífer, concretament).

3.- Estudi i reconeixement de la Depressió Geològica de l’Ebre (i més concretament de la seva Depressió Central), la qual tallarem al llarg de bona part del recorregut de l'itinerari, i en especial entre les localitats de Cabra del Camp i Sarral. I alhora, reconeixement dels materials cenozoics que la reblen: aquests materials pertanyen, en tots els casos, a l'Eocè i a l'Oligocè. Aquests materials es distribueixen fonamentalment entre les següents unitats litostratigràfiques: Formació Tàrrega, Grup Pontils (Formació Valldeperes i Formació Bosc d'en Borràs), Formació Blancafort, Formació Montsant, Formació Montblanc, Formació Sarral i Conglomerats de Sant Miquel de Montclar.

4.- Estudi dels contactes entre les unitats geològiques acabades d'esmentar: entre el Sistema Mediterrani i la Depressió Geològica de l'Ebre. I entre les diferents sots unitats que les constitueixen.

5- Estudi mineralògic i mineralogenètic de diferents indicis situats al llarg del recorregut, com les mineralitzacions evaporítiques guixoses, les quals es troben prop de la població de Sarral, a la Depressió Geològica de l’Ebre.

6.- Visió de les diferents explotacions dels georrecursos situats al llarg del recorregut de l'itinerari. Així, tant de les mineralitzacions esmentades a l'apartat anterior, com de les explotacions de guixos que trobarem prop de Sarral.

7.- Si s’escau, visió de les tasques de restauració mediambientals realitzades a partir de les explotacions dels georrecursos.

8.- Observació dels diferents indrets, al llarg del recorregut, relacionats amb el nostre Patrimoni Geològic i Miner. Entre aquests indrets, cal fer esment de la Font Major, de la que hem parlat abans. 


\section{ANTECEDENTS}

Cal fer esment de diferents antecedents, relatius a altres itineraris coincidents parcialment amb el present. Es tracta de diversos treballs nostres, concretament de: MATAPERELLÓ (1995, 1996, 1997, 1998, 1999, 2000 i 2004). Tret d'aquests, no coneixem cap altre itinerari geològic que es desenvolupi pels indrets pels quals passarà el present. Tot i això, els esmentats discorren pels voltants de Sarral, no havent cap recorregut entre el Pla de Santa Maria i Sarral, essent aquest el primer.

Pel que fa als materials terciaris de la Depressió Geològica de l'Ebre, cal fer esment dels estudis realitzats per COLOMBO (1986 i 1989). Aquest autor va definir una sèrie de formacions litostratigràfiques, situades precisament en la zona per la qual discorre la major part del recorregut de l'itinerari. També hem de fer esment de diversos antecedents relatius als caràcters geològics generals, es tracta dels treballs de: GUIMERÀ et altri (1992); i també de RIBA et altri (1979).

Pel que fa a l'estudi dels indicis minerals, cal fer esment dels estudis efectuats per MATA-PERELLÓ (1991), dedicat al conjunt dels indicis minerals catalans.

Ens remetem, pel que fa als treballs esmentats, a l'apartat dedicat a les REFERÈNCIES BIBLIOGRÀFIQUES.

\section{RECORREGUT DE L'ITINERARI}

El recorregut de l'itinerari s’inicia prop de la localitat del Pla de Santa Maria (o Pla de Cabra), per on es realitzarà la primera aturada de l'itinerari, molt prop del poble. Tot seguit, es dirigirà cap al proper poble de Figuerola del Camp, anant cap al Nord (o millor cap al NNW). Prop d'aquest poble, s'efectuarà una nova aturada.

Després, el recorregut es dirigirà cap al poble de Cabra del Camp, prop d'on es farà una nova aturada, Tot seguit, el recorregut es dirigirà cap a la localitat de Sarral, per on es realitzaran diverses aturades a antigues explotacions mineres. Després, el recorregut anirà cap a llevant, per tal d'arribar a Sant Miquel de Montclar, per on finalitzarà el recorregut, abans s’haurà passat per Rocafort de Queralt i per Vallverd de Queralt.

\section{DESCRIPCIÓ DE L'ITINERARI}

Com en altres itineraris, aquest recorregut s'estructurarà en una sèrie de PARADES o d'ESTACIONS que anirem veient a continuació. En cada una d'aquests aturades es farà un breu comentari, relatiu als trets geològics més importants; així com als accessos a cada un dels indrets.

En cada cas s'haurà situat el nom del municipi on es troben (o el de la localitat agregada més propera) i el de la comarca (que en aquest cas serà o de l'Alt Camp o el de la Conca de Barberà; tot i així, farem esment de la subcomarca, si s'escau). Per d'altra banda, darrera del 
nom de l'indret situarem (entre parèntesi) el número del full del Mapa Topogràfic, a escala 1:50.000, on es troba situat l'indret. En aquest itinerari, sols utilitzarem un full, el següent: 418 (o de Montblanc). Aquest full ha estat publicats per l'Instituto Geográfico y Catastral de España.

Així doncs, la relació general ordenada de les parades que composen aquest recorregut, és la següent.

PARADA 1 - CONDICIONAL. INMEDIACIONS DEL PONT SOBRE EL BARRANC SEC, CARRETERA A VALLS, (terme municipal de Pla de Santa Maria, o del Pla de Cabra, comarca de l'Alt Camp). (Full 418).

Aquest recorregut l'haurem iniciat a la capital comarcal, a Valls. Des d'enllà ens cal agafar la carretera C - 37, anant cap al poble del Pla de Santa Maria (o Pla de Cabra). Però en arribar al pontet sobre el Barranc Sec caldrà fer la present aturada, després de recórrer uns $6 \mathrm{Km}$, des de la població de Valls.

En aquest recorregut, hem anat trobant afloraments dels materials miocènics $i$ quaternaris que reblen la Depressió Prelitoral Catalana, on ens trobem ara situats. Precisament, aquests darrers materials es troben també a l'indret on ara estem situats.

Des d'aquest indret, tot mirant cap a llevant, es pot veure com la Serralada Prelitoral Catalana (el Massís de Bonastre), tenca a la depressió on estem,i situats. Igualment, mirant cap al Nord i cap a l'Oest, es pot veure com la Serralada Prelitoral Catalana, la tenca per aquests darrers indrets esmentats.

\section{PARADA 2. IMMEDIACIONS DELS MASOS, (terme municipal de Figuerola del Camp, comarca de l'Alt Camp). (Full 418).}

Després de realitzar l'aturada anterior, cal acabar d'arribar al Pla de Santa Maria. Després, ens caldrà agafar la carretera TV - 2001, la qual ens durà cap al proper poble de Figuerola del Camp. En arribar-hi farem una nova aturada, per les immediacions dels Masos, situats a uns $1^{\prime} 5 \mathrm{Km}$ al Oests del poble. Així, des de la parada anterior haurem recorregut uns 4,5 Km, per tal d'arribar fins aquí.

Com al cas anterior, en aquest recorregut, hem anat trobant afloraments dels materials miocènics i quaternaris que reblen la Depressió Prelitoral Catalana, situada prop d'on ens trobem ara situats. Tot i així, en arribar al poble, hem començat a trobar afloraments dels materials triàsics i del Carbonífer. Així, haurem entrat a la Serralada Prelitoral Catalana, on ens trobem ara situats.

En aquest indret, entre els materials de la Serralada Prelitoral Catalana, apareixen unes roques ígnies. Aquestes roques es troben dintre de l'esmentada serralada. Es tracta d'unes roques de composició propera als basalts. 
PARADA 3. ELS MOLINETS, CARRETERA A CABRA DEL CAMP, (terme municipal de Cabra del Camp, comarca de la Conca de Barberà). (Full 418).

Després de fer l'aturada anterior, cal anar pel camí veïnal que condueix cap a Cabra del Camp (en realitat, cap a la carretera TP - 2311, que uneix el darrer poble amb el Pla de Santa Maria). En arribar a aquesta carretera, ens caldrà anar cap al Nord. En arribar als Molinets (poc abans de Cabra), ens caldrà fer una nova aturada. Així, des de l'anterior, haurem recorregut poc més de $4 \mathrm{Km}$, per tal d'arribar fins on ara som.

En aquest recorregut (fet íntegrament dintre de la comarca de l'Alt Camp), haurem circulat per la zona de contacte entre la Depressió Prelitoral Catalana (Depressió del Camp) i la Serralada Prelitoral Catalana, que es troba al Nord . Cal dir que la zona de contacte ha quedat fossilitzada pels materials detrítics quaternaris.

A l'indret on ara som, es poden veure els afloraments dels materials triàsics (discordants amb els paleozoics). Aquests terrenys pertanyen al Buntsandstein i al Muschelkalk. Aquests materials formen un congost, per on discorre el Torrent de la Fonollosa.

\section{PARADA 4. EXPLOTACIONS DE CALCOLUTITES DE LA SALADA, (terme municipal de Sarral, comarca de la Conca de Barberà). (Full 418).}

Des de la parada anterior, cal continuar cap a la població de Cabra del Camp, per tal de continuar després cap al Nord, seguint sempre la carretera TP - 2311, fins arribar a Sarral. En arribar-hi, ens caldrà travessar la població, per tal d'agafar la carretera T-233, la qual es dirigeix cap al Nord. A menys de $1 \mathrm{Km}$ després del poble, ens caldrà fer una nova aturada. Així, des de l'anterior parada, haurem recorregut uns 8'5 Km i escaig.

Tot aquest recorregut, s'ha fet per la Depressió Geològica de l’Ebre (i més concretament per la seva Depressió Central). Així inicialment s'ha circulat per entre els afloraments de la Formació Blancafort (amb trams ocres, lutítics i sorrencs), la qual forma part dels sectors distals del Complex Al-luvial del Montsant. Més endavant hem començat a trobar els materials que formen part del Complex Al-luvial de l'Anoia; i en especial pels de la Formació Sarral, constituïts per trams calcolutítics, de tonalitats clares.

Aquest indret, com la totalitat dels indrets per on discorrerà el present itinerari, es troba situat dintre de la Depressió Geològica de l'Ebre (i més exactament: de la seva Depressió Central). Així, per arreu es troben els sediments cenozoics esmentats a les aturades anteriors, coberts ocasionalment per terrenys quaternaris.

A l'entrada de la fàbrica es fa força palès un nivell de guixos (dels que parlarem a la propera aturada), i per sobre d'ells afloren unes calcolutites ocres, que han estat explotades per a una antiga fàbrica de ciment ràpid. Aquestes calcolutites pertanyen als trams intermitjos del Complex al·luvial de l'Anoia, que son els materials que afloren per arreu.

Finalment, cal dir que les antigues explotacions es troben força malmesos, i són ara emprades com a dipòsits de runa. És a dir: es tracta d'un patrimoni miner en avençat estat de pèrdua irreversible. 
PARADA 5. PEDRERES D'ALABASTRE DE LA SALADA, (terme municipal de Sarral, comarca de la Conca de Barberà). (Full 418).

Des de la parada anterior, cal retornar a la carretera. Poc desprès, cal agafar un corriol (abans de passar el pont) que se'n va cap a ponent. En uns $100 \mathrm{~m}$ s'arribarà a les antigues guixeres de la Salada, a menys de 0`5 Km de la parada anterior.

Així, en aquest indret, ens troben enmig d'un aflorament de guixos que pertanyen als Nivells de Guixos de Pira-Sarral (que s'inclouen a la Formació Sarral). Els nivells es troben formats per alternances de guixos i de calcolutites rogenques (i ocasionalment, amb presència de trams de dolomies amb sílex). Cal dir també, que aquests materials s'inclouen dintre del Complex Al·luvial de l'Anoia.

Precisament, en aquest indret s'han explotat, temps enrere, els nivellets de guixos, de cara a la seva utilització com alabastres. Entre els minerals presents, a més a més del GUIX (que és el mineral majoritari, i que es presenta molt compacte), hi ha: ANHIDRITA i HEMIHEDRITA. També hi ha CALCITA i CAOLINITA.

Finalment, cal dir que aquests materials guixosos sovint han estat emprats com alabastre, donant un cert renom a la localitat de Sarral, per aquest tema. Tot i així, a l'actualitat. molt del guix que es treballa, procedeix d'altres llocs, i especialment dels voltants de Fuentes de Ebro (Saragossa).

PARADA 6. PRESA ROMANA, BARRANC DE LA SALADA, (terme municipal de Sarral, comarca de la Conca de Barberà). (Full 418).

Des de la parada anterior, cal retornar a la població de Sarral, per tal de fer ara una fillola cap a ponent, amb la intenció de retrobar el barranc de la Salada. Així, poc després de tornar al poble i sortir per la carretera C - 241, trobarem els cartells indicatius que anuncien la presa. En arribar-hi, farem una nova aturada, a uns $3 \mathrm{Km}$ de l'anterior.

En aquest recorregut, haurem trobat afloraments dels materials anteriorment esmentats del Complex Al·luvial de l'Anoia. Així, haurem trobat afloraments dels nivells de guixos i tanmateix de les calcolutites. Aquestes darreres predominen a l'indret de l'aturada.

En aquest lloc va haver-hi una presa, feta amb la intenció d'emmagatzemar les aigües del barranc de la Salada. El vas de la presa estaria situat sobre els afloraments calcolutitics. A l'actualitat, encara es conserven les restes. Aquest indret constitueix un interessant patrimoni arquitectònic i fins i tot miner (ja que la intenció era l'aprofitament dels recursos geològics hídrics del barranc de la Salada).

PARADA 7 - CONDICIONAL. PEDRERES D'ALABASTRE de COMA RALS (terme municipal de Sarral, comarca de la Conca de Barberà). (Full 418).

Des de la parada anterior, cal retornar a la carretera C-241. Posteriorment, caldrà anar cap a l'indret de Coma Rals, situat a uns $2 \mathrm{Km}$ de Sarral cap al seu ponent, prop de la 
carretera C-241. En aquest lloc realitzarem una nova aturada, a uns $2 \mathrm{Km}$, des de la parada anterior.

Tot aquest recorregut, s'ha fet per la Depressió Geològica de l'Ebre (i més concretament per la seva Depressió Central). Així s'han anat trobant els materials que ja hem trobat a la parada anterior, del Complex Al-luvial de l'Anoia; i en especial pels de la Formació Sarral, constituïts per trams calcolutítics, de tonalitats clares.

Ara, en aquest indret, ens troben enmig d'un aflorament de guixos que pertanyen als Nivells de Guixos de Pira-Sarral (Formació Sarral). Els nivells es troben formats per alternances de guixos i de calcolutites rogenques (i ocasionalment, amb presència de trams de dolomies amb sílex). Cal dir també, que aquests materials s'inclouen dintre del Complex Al·luvial de l’Anoia.

Precisament, en aquest indret s'han explotat, temps enrere, els nivellets de guixos, de cara a la seva utilització com alabastres. Entre els minerals presents, a més a més del GUIX (que és el mineral majoritari, i que es presenta molt compacte), hi ha: ANHIDRITA i HEMIHEDRITA. També hi ha CALCITA i CAOLINITA.

PARADA 8. IMMEDIACIONS DE L'ERMITA DE SANT MIQUEL DE MONTCLAR, (Vallespinosa, terme municipal de Santa Perpètua de Gaià, comarca de la Conca de Barberà, subcomarca de la Baixa Segarra). (Full 418).

Després de fer l'aturada anterior, cal retornar cap a Sarral. Un cop aquí, seguint per la carretera comarcal C-241, cal anar cap a llevant. Així, aviat es passarà per Rocafort de Queralt. Més endavant es deixarà a la dreta el trencall de Vallverd, per a trobar després el de Vallespinosa, que ens caldrà agafar. Per ell arribarem a les immediacions de l'ermita de Sant Miquel de Montclar. En vistes al turó on es troba l'ermita, farem una nova aturada, a uns 14 Km de la darrera, feta prop de Sarral.

En aquest recorregut, inicialment hem anat trobant els materials de la Formació Sarral (amb trams blanquinosos de calcolutites i guixos). Tot i així, prop de Rocafort haurem trobat els nivells de la Formació Montblanc, amb calcolutites rogenques, així com gresos i conglomerats.

Tot i així, a l'indret on som ara es fan força palesos els nivells de conglomerats que formen el turó enlairat de l'ermita. Constitueixen els denominats conglomerats de Sant Miquel de Montclar. Aquests nivells enlairats donen lloc a aquests relleus, els quals s'inclouen dintre del que vam denominar com a Altiplans Meridionals de la Depressió Geològica de l'Ebre (MATA-PERELLÓ, 1995).

\section{EN AQUEST INDRET FINALITZA EL RECORREGUT DE L'ITINERARI}




\section{BIBLIOGRAFIA}

COLOMBO,F. (1986).- Estratigrafia y Sedimentologia del Paleogen continental del borde meridional occidental de los Catalánides (província de Tarragona). Cuadernos de Geologia Ibérica, vol. 10,pp. 55-115. Madrid

COLOMBO,F. (1989).- El Montsant: aspectes geològics (en "1O sortides per la Catalunya Sud"). 2on. Sympósium sobre l'Ensenyament de les Ciències Naturals, de Tarragona. Edit. Eumo, pp. 87-108, Barcelona

GUIMERÀ, J. et altri (1992).- Geologia (II), Història Natural dels Països Catalans, Vol.2, 547 pag. Enciclopèdia Catalana, S.A. Barcelona

MATA-PERELLO,J.M. (1991).- Els minerals de Catalunya. Institut d'Estudis Catalans. Arxius de la Secció de Ciències, t.XLVIII. 506 pag. Barcelona

MATA-PERELLÓ, J.M. (1995).- Itinerari geològico-mineralògic per les comarques d'Anoia, Baixa Segarra, Conca de Barberà i Alt Camp: des d'Òdena a Miralles, a Sarral i al Pont d'Armentera. Inèdit, 12 pàgines. Manresa

MATA-PERELLÓ, J.M. (1996).- Itinerari de recerca geològica i mineralògica per les comarques de la Conca de Barberà, Priorat i Ribera d'Ebre: des de Vimbodí a Margalef i a Mora d’Ebre, Inèdit, 12 pàgines. Manresa

MATA-PERELLÓ, J.M. (1997a).- Recorregut de recerca geològica i mineralògica per les comarques d'Anoia, Segarra, Baixa Segarra i Conca de Barberà: des de la Panadella a Santa Coloma de Queralt, i de Valdeperes a Sarral i a Prenafeta. Inèdit, 16 pàgines, Manresa

MATA-PERELLÓ, J.M. (1997b).- Recorregut de recerca geològica i mineralògica per les comarques de les Garrigues i de la Conca de Barberà: des de Vinaixa a l’Espluga de Francolí i a Rojals. Inèdit. 16 pàgines. Manresa

MATA-PERELLÓ, J.M. (1998).- Recerca geològica i mineralògica per la Conca de Barberà, pel Priorat i per les Garrigues: des de Sarral a Vimbodí, i d’Ulldemolins a Margalef i a la Pobla de Cèrvoles. Inèdit, 16 pag. Manresa

MATA-PERELLÓ, J.M. (1999).- Recerca Geològica i Mineralògica per la Conca de Barberà: des de Santa Coloma de Queralt a Sarral i des de Montblanc a Rojals. Inèdit, 14 pag. Manresa

MATA-PERELLÓ, J.M. (2000).- Recorregut de Recerca Geològica i Mineralògica per les comarques de les Garrigues, de la Conca de Barberà i del Priorat: des de Sarral a Blancafort, Poblet, Ulldemolins, Vinaixa i a l’Espluga Calba. Inèdit, 20 pag. Manresa

MATA-PERELLÓ, J.M. (2004).- Recerca geològica i mineralògica per la Conca de Barberà: des de l'Espluga de Francolí a Sarral, a Santa Coloma de Queralt i a Valdeperes. Inèdit. 10 pàgines. Manresa

RIBA, O. et altri (1976).- Geografia Física dels Països Catalans, Edit. Ketres, 254 pàgines. Barcelona 
